\title{
Efeitos do parasitismo por Ichthyophthririus multifiliis sobre as brânquias de pacu (Piaractus mesopotamicus) (OSTEICHTHYES: CHARACIDAE)
}

\author{
[Effects of parasitism by Ichthyophthririus multifiliis on pacu gills (Piaractus mesopotamicus) \\ (OSTEICHTHYES: CHARACIDAE)]
}

\section{"Artigo Científico/Scientific Article"}

\author{
Arlene Sobrinho Ventura ${ }^{1 *}$, Juliana Simeão dos Santos $^{2}$, Angelina Nunes Vieira ${ }^{3}$, Joyce Zanella ${ }^{3}$, \\ Andrea Maria de Araújo Gabriel ${ }^{3}$
}

\author{
${ }^{1}$ Faculdade de Medicina Veterinária e Zootecnia, Universidade Federal de Mato Grosso do Sul, Campo Grande-MS, \\ Brasil. \\ ${ }^{2}$ Médica Veterinária Autônoma, Dourados-MS, Brasil. \\ ${ }^{3}$ Faculdade de Ciências Agrárias, Universidade Federal da Grande Dourados, Dourados-MS, Brasil. \\ *Autor para correspondência/Corresponding author: E-mail: arlenesventura@gmail.com
}

\begin{abstract}
Resumo
As brânquias se caracterizam por serem órgãos respiratórios de peixes teleósteos, que podem ser parasitados por protozoários dificultando as trocas gasosas. Com este trabalho objetivou-se descrever os danos causados à estrutura tecidual das brânquias de pacu (Piaractus mesopotamicus), durante fase inicial de criação, pelo protozoário Ichthyophthririus multifiliis. Um total de cinquenta alevinos de P. mesopotamicus foi coletado em fevereiro de 2017 em piscicultura comercial, com surto de doença dos pontos brancos. Ao realizar exame microscópio das brânquias observou-se que todos os animais estavam parasitados naturalmente por $I$. multifiliis. Após análise histológica das brânquias foi possível constatar que havia severas lesões branquiais como congestão, telangiectasia, hemorragia intersticial, edema sub-eptelial, hiperplasia epitelial e de células mucosas e reação inflamatória moderada, localizadas nos filamentos e lamelas sendo frequente a fusão lamelar. No entanto observa-se que as lesões ocasionadas por I. multifilis em brânquias de P. mesopotamicus, são respostas inespecíficas do hospedeiro à agressão
\end{abstract}

Palavras-chave: alevino; doença; histopatologia; peixe.

\begin{abstract}
Gills are respiratory organs of teleost fish, which can be parasitized by protozoa, making gas exchanges difficult. The objective of this work was to describe the damage caused to the tissue structure of pacu gills (Piaractus mesopotamicus), during the initial stage of creation, by the protozoan Ichthyophthririus multifiliis. A total of fifty fingerlings of P. mesopotamicus were collected in February 2017 at a commercial fish farm with a white spot disease outbreak. When performing a microscopic examination of the gills, it was observed that all the animals were parasitized naturally by I. multifiliis. After histological analysis of the gills, it was possible to observe that there were severe gill-like lesions, such as congestion, telangiectasia, interstitial hemorrhage, subepithelial edema, epithelial and mucosal cell hyperplasia, and moderate inflammatory reaction located in lamellar filaments. However, it is observed that the lesions caused by I. multifilis in gills of $P$. mesopotamicus are nonspecific responses of the host to the aggression.
\end{abstract}

Keywords: disease; fish; fry; histopathology.

\section{Introdução}

O protozoário ciliado Ichthyophthirius multifiliis (Fouquet, 1876) é um dos parasitos mais patogênicos em peixes cultivados (Dickerson, 2006), constituindo um grande problema de enfermidades na aquicultura. Este parasito é

causador da doença dos pontos brancos ou ictiofitiríase. É considerado cosmopolita e não possui especificidade parasitária, sendo encontrado em populações de peixes cultivados e selvagens (Dickerson, 2006). Localiza-se principalmente na 
pele e nas brânquias dos peixes, provocando grandes prejuízos nas pisciculturas de água doce de todo o mundo (Buchmann et al., 2001).

Embora todas as espécies de peixes de água doce sejam suscetíveis a I. multifiliis, o grau de suscetibilidade varia (Ventura e Paperna, 1985), de acordo com fatores genéticos, condições ambientais e a população parasitaria (Price e Clayton, 1999). Além disso, este parasito favorece a ocorrência de infecções bacterianas oportunistas (Xu et al., 2012a; Xu et al., 2012b), além de servir como reservatório e vetor de bactérias patogênicas (Liu e Lu, 2004).

O aparecimento da doença é facilitado em locais que ocorrem variações bruscas da temperatura e má qualidade de água, o que ocasiona estresse nos peixes (Pavanelli et al., 2008). Alguns sinais clínicos de peixes infectados com I. multifiliis são pontos brancos na superfície corporal e brânquias além de aumento na produção de muco (Dickerson, 2006).

A brânquia é um órgão multifuncional responsável pela respiração, o principal local para excreção de produtos nitrogenados e possui um importante papel no balanço de íons (Noga, 2010). Este órgão é altamente suscetível à infecção, e o dano branquial resultante contribui consideravelmente para os efeitos letais causados pelo parasita (Dickerson, 2006).

No Brasil, vários estudos relatam a infestação por I. multifiliis em Piaractus mesopotamicus em sistemas de cultivo (Tavares Dias et al., 1999, 2001; Martins et al., 2000; Francechini et al., 2013; Jerônimo et al., 2015). Assim como em seus híbridos patinga (Piaractus mesopotamicus $\mathrm{x}$ Piaractus brachypomus) (Francechini et al., 2013; Jerônimo et al., 2015) e tambacu (Colossoma macropomum x Piaractus mesopotamicus) (Silva et al., 2013; Jerônimo et al., 2015). No entanto, poucos são os estudos relatando a doença causada por infecção por esses parasitos nesta espécie de peixe (Martins e Romero, 1996). Diante disto objetivou-se, com este trabalho, descrever as alterações histopatológicas em alevinos de pacus (Piaractus mesopotamicus), parasitados naturalmente pelo protozoário Ichthyophthririus multifiliis.

\section{Materiais e Métodos}

Foram avaliados cinquenta alevinos de $P$. mesopotamicus coletados em fevereiro de $2017 \mathrm{em}$ piscicultura comercial localizada no município de Dourados (22 $12^{\circ} 16^{\prime \prime} \mathrm{S} ; 54^{\circ} 48^{\prime} 20^{\prime \prime} \mathrm{W}$, altitude: 430m), Estado de Mato Grosso do Sul, Brasil. Os animais apresentavam peso médio de $37,48 \pm 10,56 \mathrm{~g}$ e comprimento médio de $13,20 \pm 2,17 \mathrm{~cm}$, foram capturados para avaliar a infestação por ectoparasitos. Para realizar o diagnóstico, os peixes foram capturados aleatoriamente, sacrificados por aprofundamento anestésico em solução alcoólica de óleo de cravo (50 $\mathrm{mg} \mathrm{L} \mathrm{L}^{-1}$ ). Os animais foram avaliados macroscopicamente, observando-se a superfície corporal, nadadeiras, brânquias e opérculos quanto à presença de sinais de ectoparasitoses. Feito isto, foram confeccionadas lâminas do raspado de muco e da brânquia, para observação, em microscopia de luz (Jerônimo et al., 2011).

As brânquias foram examinadas em conjunto e individualmente, investigando-se a presença de eventuais alterações de tamanho, consistência, coloração, presença de fluidos, assim como de parasitos. Coletou-se também fragmentos das brânquias para análise histológica, sendo fixados em formalina tamponada a $10 \%$ e processados segundo as técnicas histológicas usuais para obtenção de cortes seriados em parafina, com 5,0 micras de espessura. As secções obtidas foram coradas pela hematoxilina-eosina e azul de toluidina, dependendo da necessidade (Michalany, 1990). A pesquisa, colheita e identificação parasitológica foi realizada de acordo com as recomendações de Eiras et al. (2006) e Jerônimo et al. (2011).

\section{Resultados}

Os peixes capturados apresentavam-se apáticos, nadando na superfície dos viveiros, próximos à entrada de água. As brânquias apresentavam excesso de muco, coloração vermelha intensa, petéquias, áreas pardacentas, irregulares e de tamanhos variados. Ao exame microscópico diagnosticou-se alta infestação pelo protozoário I. multifiliis, localizados na base dos filamentos e nos espaços inter-lamelares (Figura 1a e 1b).

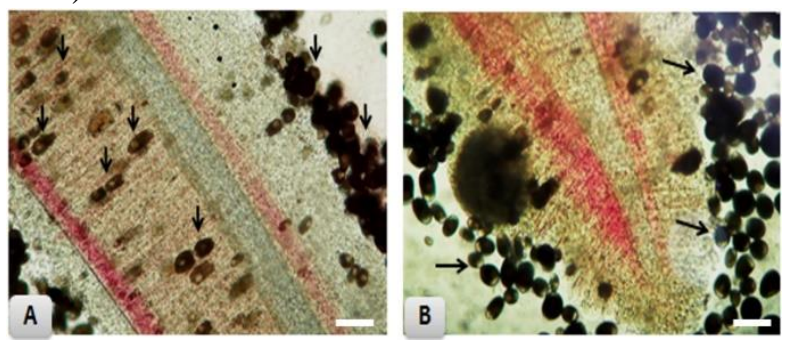

Figura 1. Brânquias de alevinos de pacu (Piaractus mesopotamicus) parasitados por Ichthyophthirius multifiliis no exame direto em microscopia de luz. Aumento 10x. - Escala $100 \mu \mathrm{m}$. 
Os peixes parasitados apresentaram graus variados de alterações patológicas, as lesões encontradas foram hiperplasia epitelial e mucosa nas lamelas, congestão, hemorragia intersticial e pequenos edemas sub-epiteliais (Figura. 2). O parasito observado no exame histopatológico foi o mesmo diagnosticado no exame parasitológico.

As alterações histológicas encontradas incluíram destacamento do epitélio de revestimento da lamela secundária, micro hemorragias, infiltração de células inflamatórias nos filamentos, desorganização lamelar, parasito aderido a lamelas. Ainda foi observado nas regiões inter-lamelares modificações na distribuição das células epiteliais com espaços intercelulares, destacamento do epitélio respiratório e congestão sanguínea dos capilares das lamelas seguido de presença de célula granular eosinofílica no interior do vaso do filamento, telangectasia, edema intertiscial. Alguns exemplos de lesões mais graves encontradas, foram aneurismas lamelares e hemorragias com ruptura do epitélio lamelar (Figura 2).

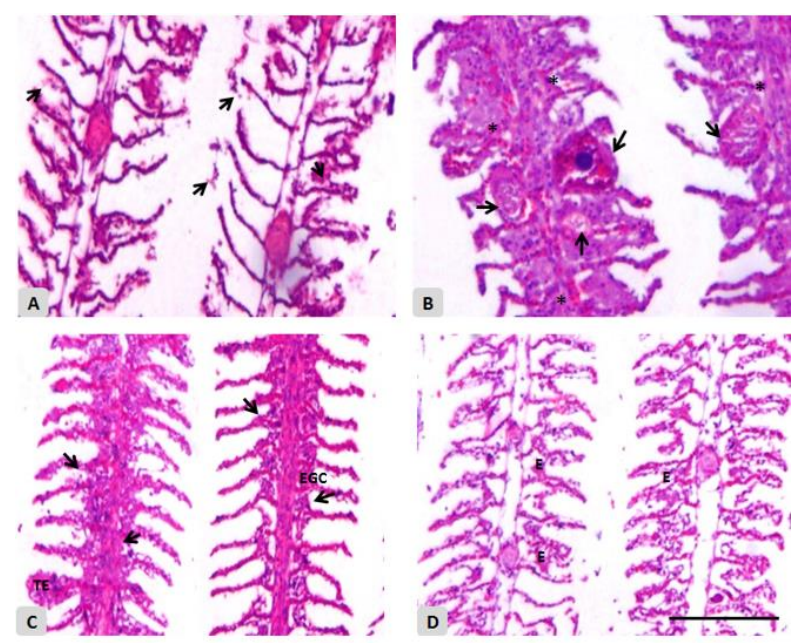

Figura 2. Cortes de filamentos branquiais de alevinos de pacu (Piaractus mesopotamicus). A- destacamento do epitélio de revestimento da lamela secundária (setas); B- Fusão lamelar, micro hemorragias, infiltração de células inflamatórias nos filamentos (*), desorganização lamelar, parasito aderidos a lamelas (seta); C - A regiões inter-lamelares apresentaram modificações na distribuição das células epiteliais com espaços intercelulares, destacamento do epitélio respiratório e congestão sanguínea dos capilares das lamelas e presença de célula granular eosinofílica na região inter-lamelar e no interior do vaso do filamento (EGC), Telangectasia (TE); D- edema intertiscial (E). Aumento 10x. Coloração HE- Escala $100 \mu \mathrm{m}$.

Houve vasodilatação e congestão nos capilares lamelares e no interior do vaso capilar central, parasito na base das lamelas, fusão das lamelas secundárias, aneurisma, descolamento do epitélio provavelmente devido a edema subepitelial e desorganização lamelar (Figura 3). Os parasitos encontrados nos cortes histológicos estavam envoltos por camada de tecido epitelial seguido de reação inflamatória.

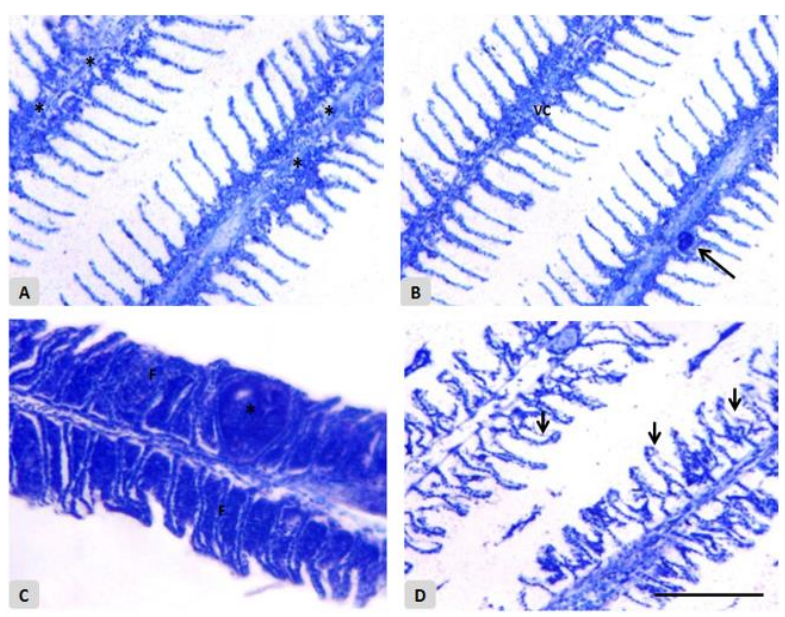

Figura 3. Cortes histológicos de brânquias de alevinos de pacu (Piaractus mesopotamicus). A- observam-se vasodilatação e congestão nos capilares lamelares e interior do vaso capilar central (*); B- congestão vascular (vc) no vaso central do filamento branquial, parasito na base das lamelas (seta); C- fusão das lamelas secundárias $(\mathrm{F})$, aneurisma $(*)$; Ddescolamento do epitélio provavelmente devido a edema sub-epitelial (Setas). Aumento 10x. Coloração Azul de Toluidina- Escala $100 \mu \mathrm{m}$.

\section{Discussão}

Estudos histopatológicos são considerados fortes adjuvantes no que diz respeito ao diagnóstico da saúde dos peixes, especialmente para os peixes cultivados (Martins et al., 2015), possibilitando a detecção da lesão que os parasitas causam em seus hospedeiros (Pádua et al., 2014). Os animais avaliados apresentavam-se alteração de comportamento e com sinais de necessidade de oxigênio, como foi também observado por Schalch et al. (2006) em piauçu (Leporinus macrocephalus) parasitados por Henneguya leporinicola nas brânquias. As brânquias são órgãos sensíveis a agressões, o que faz com que as lesões no tecido branquial sejam as mais preocupantes.

Os animais infestados por I. multifiliis, apresentaram sinal patognomônico da doença no local parasitado como pontos brancos em formas e tamanhos diferentes no tegumento, nadadeiras e brânquias, provocando hiperplasia das células de muco e impermeabilização das brânquias. Lesões semelhantes foram observadas por Martins \& Romero (1996) ao avaliarem os efeitos do parasitismo sobre o tecido branquial de peixes 
cultivados. De acordo com Padua et al. (2012), em resposta a agressão do parasito as brânquias, os peixes infectados apresentam hiperplasia do epitélio e células mucosas, condicionando a uma maior produção de muco, com infiltrado inflamatório composto por granulócitos e células mononucleares. Peixes portadores de infecção por monogenóides e outros parasitos branquiais, também apresentam, como resposta, estas lesões (Schalch et al., 2006).

A hiperplasia é uma reação do epitélio à irritação crônica por agentes químicos (Romano e Cueva, 1988). Também pode ser reação à uma lesão causada pela infestação de parasitos (Del Rio-Zagaroza et al., 2010; Raissy e Ansari, 2011) podendo se agravar, devido a uma combinação de fatores que ocorrem dentro de um sistema artificial de cultivo (Del Rio-Zagaroza et al., 2010). Estudos de Raissy e Ansari (2011) relataram hiperplasia, congestão e aumento número de células mucosas em Capoeta aculeata parasitado por I. multifiliis, Trichodina sp. (Ciliophora), Myxobolus musayevi (Myxozoa), Dactylogyrus extensus, Gyrodactylus sp. (Monogenea) e copepodídeos de Lernaea cyprinacea (Crustacea). Em P. mesopotamicus parasitados por de $H$. piaractus, monogenóides, Trichodina sp., foi observado hiperplasia epitelial e mucosa, fusão e destruição da lamela secundária (Schalch et al., 2006).

De acordo com Dickerson (2006) a produção de muco aumentada combinada com a secreção das glândulas cefálicas resulta em fusão das lamelas secundárias e impermeabilização do epitélio branquial, corroborando com observado no presente estudo. $\mathrm{O}$ muco $\mathrm{e}$ as células mononucleares atuam no mecanismo de defesa orgânica do animal, devido a suas propriedades antimicrobianas, pela ação de lisozimas, anticorpos e ácidos graxos de baixo peso molecular (Roberts, 2001). Além de que pode provocar resposta inflamatória com migração de trombócitos, macrófagos, linfócitos e granulócitos eosinofílicos que levam a hiperplasia de células epiteliais, cálices e cloretos (Del Rio-Zaragoza et al., 2010). As lamelas são responsáveis pelas trocas gasosas, equilíbrio osmorregulatório e ácido-básico (Thatcher e Brites-Neto, 1994). Assim em casos de fusão lamelar ocorre asfixia e acúmulo de compostos tóxicos no sangue, como a amônia (Padua et al., 2012) podendo causar a morte dos animais.

A transmissão do parasito é facilitada devido ao seu ciclo de vida que é monoxeno, com três estágios: trofonte, tomonte e teronte. Segundo Martins et al. (2015), as alterações patológicas associadas ao I. multifilis, estão relacionadas com a invasão do teronte sobre as camadas do epitélio com posterior histofagia na fase de trofonte. Carneiro et al. (2006) observaram, em estudo anatomopatológico com alevinos de jundiá parasitados por I. multifilis que a hiperplasia epitelial e hiperemia em lamelas secundárias nos locais de fixação dos trofontes ocasiona diminuição dos espaços inter-lamelares em função dos parasitas, limitando significativamente a área de superfície disponível para as trocas gasosas. Em resposta a diminuição dos espaços inter-lamelares, o organismo do peixe reage aumentando o número de células epiteliais próximas para melhorar a captação de oxigênio (Moreira et al., 2001).

Os trofontes aderidos à base das lamelas, recobertos por uma camada de tecido epitelial prejudicam a capacidade respiratória, do hospedeiro principalmente em fases iniciais de criação (Pádua et al., 2012), pois interferem nas trocas gasosas e na excreção de metabólitos realizadas pelas brânquias dos peixes. Além que conferem susceptibilidade aos peixes frente às infecções secundárias por bactérias e fungos, podendo culminar em surtos de mortalidades (Xu et al., 2012a; Xu et al., 2012b; Liu e Lu, 2004). Segundo Maki et al. (2001), a presença de trofontes na base dos filamentos primários e também dentro do epitélio das brânquias, causa hiperplasia epitelial, e oclusão dos filamentos secundários em bagre americano (Ictalurus punctatus) parasitados por I. multifiliis.

O encapsulamento dos trofontes aderidos à base das lamelas branquiais, por uma camada de tecido epitelial, ocorre como resposta do hospedeiro à ação do protozoário. Foi observado por Martins e Romero (1996), nas brânquias de tambacus (28\%), Colossoma macropomum $(19,1 \%)$ e P. mesopotamicus $(7,2 \%)$, trofontes aderidos na base das lamelas, envoltos por uma camada de tecido epitelial, apresentando restos de células semi-digeridas e vacúolos com resquícios celulares no seu citoplasma. Esse tipo de resposta também foi observado em $P$. mesopotamicus parasitados por Henneguya sp. no estudo de Martins et al. (1997).

Algumas lesões são ocasionadas, quando o ciliado atinge a forma madura, rompendo o epitélio para retornar ao ambiente aquático e se transformar 
em tomonte (Pádua et al., 2012). No entanto a fase em que os trofontes estão localizados no epitélio branquial é a mais importante, por ser aquela que causa doença (Carneiro et al., 2006). Podendo causar danos estruturais graves, como cistos entre as lamelas e inflamação (Schalch et al., 2006; Campos et al., 2011), conforme observado no presente estudo.

As lesões variam de acordo com o grau de infecção (Schalch et al., 2006) e com o número de trofontes agrupados no mesmo local (Carneiro et al., 2006). De acordo com Padua et al. (2014) este processo provoca reação inflamatória do hospedeiro com intensa proliferação epitelial. Em casos graves pode ser observada fusão de lamelas secundárias, degeneração e necrose de células epiteliais, formando várias úlceras no epitélio, após a liberação de trofontes maduros.

A telangiectasia e aneurisma lamelar são alterações dos sinusoides branquiais e estão associados a traumas físicos ou químicos (Roberts, 2001), podendo estar ou não relacionados a lesões parasitárias. Segundo Tancredo et al. (2016), estas lesões estão presentes em animais expostos a condições estressantes, sem estarem necessariamente parasitados. Quando muitas lamelas são afetadas, conforme observado no presente estudo, a função respiratória pode diminuir especialmente em temperaturas altas, quando os níveis de oxigênio são baixos e a demanda metabólica é alta.

Segundo Dickerson (2006), a gravidade das alterações histopatológicas em peixes parasitados por I. multifiliis pode variar muito, pois o grau de gravidade das alterações é afetado por fatores que o hospedeiro estava anteriormente exposto, como estresse e estado nutricional do hospedeiro. No entanto caso esse conjunto de alterações não for tratado a tempo, pode causar um colapso branquial e a morte do hospedeiro por asfixia (Pavanelli et al., 2013).

Alterações como hiperplasia interlamelar e consequente fusão de lamelas, assim como o edema subepitelial, são consideradas alterações inespecíficas, atuam como mecanismos de defesa do órgão (Erkmen e Kolankaya, 2000), como respostas a vários tipos de agentes injuriantes e podem comprometer a função da brânquia, pois provocam o aumento da distância entre as células epiteliais e os capilares sanguíneos com prejuízo das trocas gasosas e distúrbios de osmorregulação, essenciais à sobrevivência dos animais.

\section{Conclusão}

A infecção por I. multifiliis causa lesões graves como intensa hiperplasia das células basais e mucosas, aumento da produção de muco, associada a transtornos circulatórios como congestão, telangiectasia e hemorragia intersticial. Em casos severos podem ocorrer reações inflamatórias e necrose nos filamentos branquiais. Diante disto é possível inferir que, as lesões encontradas em pacus ( $P$. mesopotamicus) parasitados por I. multifillis, se caracterizam como resposta tecidual inespecíficas.

\section{Conflito de Interesse}

Os autores declaram não existir conflito de interesse.

\section{Comitê de ética}

Este projeto de pesquisa foi aprovado pelo comitê de ética de uso de animais da Universidade Federal da Grande Dourados, sob o número 42/2016.

\section{Referências}

Buchmann, K.; Sigh, J.; Nielsen, C.V.; Dalgaard, M. Host responses against the fish parasitizing ciliate Ichthyophthirius multifiliis. Veterinary Parasitology, 100: 105-116, 2001.

Campos, C.M.; Moraes, J.R.E.; Moraes, F.R. Histopathology of gills of Piaractus mesopotamicus (Holmberg, 1887) and Prochilodus lineatus (Valenciennes, 1836) infested by monogenean and myxosporea, caugth in Aquidauana River, State of Mato Grosso do Sul, Brazil. Revista Brasileira Parasitologia Veterinária, 20: 67- 70, 2011.

Carneiro, P.C.F.; Cirio, S.M.; Schorer, M. Estudo anatomopatológico de alevinos de jundiá infectados experimentalmente por Ichthyophtirius multifiliis e submetidos a tratamentos convencionais. Archives of Veterinary Science, 11(1): 33-38, 2006.

Del Rio-Zaragoza, O.B.; Fajer-Avila, E.J.; Almazán-Rueda, P. Haematological and gill responses to an experimental infection of dactylogyrid monogeneans on the spotted rose snapper Lutjanus guttatus (Steindachner, 1869). Aquaculture and Research, 41(11): 15921601, 2010.

Dickerson, H.W. Ichthyophthirius multifiliis and Cryptocaryon irritans (Phylum Ciliophora), in: Woo, P.T.K. Fish diseases and disorders: 1. 
Protozoan and metazoan infections. $C A B$ International: Oxfordshire, 2006.p. 116-153

Eiras, J.C.; Takemoto, R.M.; Pavanelli, G.C. Métodos de estudo e técnicas laboratoriais em parasitologia de peixes. Maringá: EDUEM, 2006. 199p.

Erkmen, B.; Kolankaya, D. Effects of water quality on epithelial morphology in the gill of Capoeta tinca living in two tributaries of Kizilirmak River, Turkey. Bulletin of Environmental Contamination and Toxicology, 64: 418-425, 2000.

Franceschini, L.; Zago, A.C.; Schalch, S.H.C.; Garcia, F.; Romera, D.M.; Silva, R. J. da. Parasitic infections of Piaractus mesopotamicus and hybrid (P. mesopotamicus x Piaractus brachypomus) cultured in Brazil. Revista Brasileira Parasitolologia Veterinária, 22(3): 407-414, 2013.

Jerônimo, G.T.; Martins, M.L.; Ishikawa, M.M.; Ventura, A.S.; Tavares-Dias, M. Métodos para coleta de parasitos de peixes. Embrapa Amapá, Circular técnica, 39: 1-6, 2011.

Jerônimo, G.T.; Franceschini, L.; Zago, A.C.; Silva, R.J. da; Padua, S.B. de; Ventura, A. S.; Ishikawa, M.M.; Tavares-Dias, M.; Martins, M.L. Parasitos de peixes Characiformes e seus híbridos cultivados no Brasil. In: Tavares-Dias, M.; Mariano, W. dos S. (Org.). Aquicultura no Brasil: novas perspectivas. São Carlos: Pedro \& João Editores, v. 1, cap. 15, p. 283-304, 2015.

Liu, Y. J.; Lu, C. P. Role of Ichthyophthirius multifiliis in the Infection of Aeromonas hydrophila. Journal of Veterinary Medicine, 51(5): 222-224, 2004.

Maki, J. L.; Brown, C. C.; Dickerson, H. W. Occurrence of Ichthyophthirius multifiliis within the peritoneal cavities of infected channel catfish Ictalurus punctatus. Diseases of Aquatic Organisms, 44: 41-45, 2001.

Martins, M.L; Romero, N.G. Efectus del parasitismo sobre el tegido branquial en peces cultivados: Estudio parasitológico e histopatológico. Revista Brasileira de Zoologia, 13(2): 489-500, 1996.

Martins, M.L.; Souza, V.N.; Moraes, F.R.; Moraes, J.R.E.; COSTA, A.J.; ROCHA, U.F. Pathology and behavioral effects associated with Henneguya sp. (Myxozoa: Myxobolidae) infections of captive pacu Piaractus mesopotamicus in Brazil. Journal of the World Aquaculture Society, 28: 297-300, 1997.
Martins, M.L; Moraes, F.R.; Fujimoto, R.Y.; Onaka, E.M.; Nomura, D.T.; Silva, C.A.H.; Schalch, S.H.C. Parasitic infections in cultivated freshwater fishes. A survey of diagnosticated cases from 1993 to 1998. Revista Brasileira de Parasitologia Veterinária, 9(1): 23-28, 2000.

Martins, M.L.; Cardoso, L.; Marchiori, N.; Pádua, S.B.de. Protozoan infections in farmed fish from Brazil: diagnosis and pathogenesis. Revista Brasileira de Parasitologia Veterinária, 24(1): 1-20, 2015.

Michalany, J. Técnica histológica em anatomia patológica - com instruções para o cirurgião, enfermeira e citotécnico. $2^{\text {a }}$ ed. São Paulo: Michalany 1990, 247p.

Moreira, H.L.M.; Vargas, L.; Ribero, R.P.; Zimmermann, S. Fundamentos da moderna aquiicultura. Cidade: ULBRA, 2001. 199 p.

Noga, E.J. Fish disease: diagnosis and treatment. Iowa: Wiley-Blackwell, 2010. 378p.

Pádua, S.B.; Menezes-Filho, R.N.; Dias-Neto, J.; Jerônimo, G.T.; Ishikawa, M.M.; Martins, M.L. Ictiofitiríase: conhecendo a doença para elaborar estratégias de controle. Panorama da Aquicultura, 22-31, 2012.

Pádua, S.B.; Jerônimo, G.T.; Ishikawa, M.M.; Belo, M.A.A.; Martins, M.L.; Pelisari, T.; Carrijo-Mauad, J.R. Parasitological assessment and host-parasite relationship in farmed cachara catfish fingerlings (Pseudoplatystoma reticulatum Eigenmann \& Eigenmann 1889), Mato Grosso do Sul, Brazil. Neotropical Helminthology, 8: 37-45, 2014.

Pavanelli, G.C.; Eiras, J.C.; Takemoto, R.M. Doenças de peixes: profilaxia, diagnóstico e tratamento. $3^{\mathrm{a}}$ ed. Maringá: EDUEM, 2008. $311 \mathrm{p}$.

Pavanelli, G.C.; Takemoto, R.M.; Eiras, J.C. Parasitologia de peixes de água doce do Brasil. Maringá: Eduem, 2013. 452p.

Price, D.J.; Clayton, G.M. Interações genótipoambiente na susceptibilidade da carpa comum, Cyprinus carpio, as infecções por Ichthyophthirius multifilis. Aquaculture, 173: 149-160, 1999.

Raissy, M.; Ansari, M. Histopathological changes in the gills of naturally-infected Capoeta aculeata (Cuvier and Valenciennes, 1844) with parasites. African Journal of Biotechnology, 10: 15422-15425, 2011.

Romano, L.A.; Cueva, Y.F.O. Lesiones histologicas branquiales atribuibles a toxicos en 
Odonthestes bonariensis (Pisces, Atherinidae). Revista de la Asociación de Ciencias Naturales del Litoral, 19(2): 35-142, 1988.

Roberts, R.J. Fish pathology. $3^{\text {th }}$ ed. London: W.B. Saunders, 2001. 472p

Silva, R.M.; Tavares-Dias, M.; Dias, M.W. R.; Dias, M.K.R.; Marinho, R. das G.B. Parasitic fauna in hybrid tambacu from fish farms. Pesquisa Agropecuária Brasileira, 48(8): 1049-1057, 2013.

Schalch, S.H.C.; De Moraes, F.R.; De Moraes, J.R.E. Efeitos do parasitismo sobre a estrutura branquial de Leporinus macrocephalus garavello e britsk, 1988 (anastomidae) e Piaractus mesopotamicus Holmberg, 1887 (osteichthyes: characidae). Revista Brasileira de Parasitologia Veterinária, 15(3): 110-115, 2006.

Tavares-Dias, M.; Schalch, S.H.C.; Martins, M.L.; Silva, É.D.; Moraes, F.R.; Perecin, D. Hematologia de teleósteos brasileiros com infecção parasitária. I. Variáveis do Variáveis do Leporinus macrocephalus Garavelo e Britski, 1988 (Anostomidae) e Piaractus mesopotamicus Holmberg, 1887 (Characidae) (Characidae). Acta Scientiarum, 21(2): 337342, 1999.

Tavares-Dias, M.; Martins, M.L.; Moraes, F.R. Fauna parasitária de peixes oriundos de "pesque-pague" do município de Franca, São
Paulo, Brasil. I. Protozoários. Revista Brasileira Zoologia, 18(1): 67-79, 2001.

Tancredo, K. R.; Gonçalves, E. L. T.; Martins, M. L. Histopathological analyses of native silver catfish Rhamdia quelen (Quoy and Gaimard, 1824) immunized against and challenged with live theronts of Ichthyophthirius multifiliis Journal of Apllied Icthiology, 32: 1130-1136, 2016.

Thatcher, V.E.; Brites-Neto, J. Diagnóstico prevenção e tratamento de enfermidades de peixes neotropicais de água doce. Revista Brasileira Medicina Veterinária, 16(3): 111128, 1994.

Ventura, M.T.; Paperna, I. Histopatologia das infecções por Ichthyophthirius multifiliis em peixes. Journal Fish Biology, 27: 185-203, 1985.

Xu, D.H.; Shoemaker, C.A.; Klesius, P.H. Ichthyophthirius multifiliis as a potential vector of Edwardsiella ictaluri in channel catfish. FEMS Microbiology Letters, 329: 160-167, 2012a.

Xu, D.H.; Shoemaker, C.A.; Martins, M.L.; Pridgeon, J.W.; Klesius, P.H. Enhanced susceptibility of channel catfish to the bacterium Edwardsiella ictaluri after parasitism by Ichthyophthirius multifiliis. Veterinary Microbiology, 158(1-2): 216-219, $2012 b$. 